\title{
As humanidades no ensino
}

André Chervel

Marie-Madeleine Compère

\section{Apresentação}

A história dos currículos e das disciplinas escolares tem sido objeto de pesquisa nas últimas décadas e o interesse historiográfico sobre esta temática articula-se às indagações sobre as redefinições de políticas educacionais e problemáticas epistemológicas oriundas da denominada "crise paradigmática" dos anos 70. As décadas de 1970 e 1980 foram marcadas por políticas educacionais que, entre outras ações, cuidaram das reformulações curriculares em muitos países do mundo ocidental. Nesse processo de reformulações, a escola e o conhecimento por ela produzido tornaram-se objeto de interesse em vários países. 0 cotidiano escolar, as práticas de ensino de professores e alunos e os materiais escolares começaram a ser considerados relevantes no processo educacional e, nesta perspectiva, as disciplinas escolares tornaram-se objeto de investigação, buscando-se justificar ou compreender o papel e o significado de cada uma delas na definição dos novos currículos, e preocupando-se, entre outras dimensões, em identificar e apreender o conhecimento escolar por elas produzido.

As pesquisas da história dos currículos e das disciplinas articulam-se, assim, ao processo de transformações educacionais das últimas décadas do século XX, momento em que se repensa o papel da escola em suas especificidades e como espaço de produção de saber e não mero lugar de reprodução de conhecimentos impostos externamente. Nos anos 80 , em especial, várias reflexões sobre práticas educacionais contribuíram para a revisão de posições que concebiam a escola apenas como um dos principais aparelhos ideológicos do Estado e das classes dominantes, sem atentar para os aspectos contraditórios existentes no cotidiano da vida escolar. Verificavam-se, então, as ações dos diferentes sujeitos envolvidos no processo escolar, assim como os conhecimentos que produziam em suas dimensões mais amplas.

Um balanço, mesmo sem ser exaustivo, da trajetória da pesquisa, em uma perspectiva histórica, sobre currículos e disciplinas escolares, mostra que estas surgem em diferentes países, quase que simultaneamente e sem muitos contatos iniciais entre os que as realizavam. As investigações, entretanto, seguiram caminhos diferentes. 0 primeiro deles, notadamente realizado pelos educadores anglo-saxões, iniciava-se pela história dos currículos e, a partir deles, chegava, às vezes, às disciplinas escolares. 0 segundo percurso iniciava-se por estas, abordando as questões epistemológicas, buscando a gênese e os diferentes momentos históricos em que se constituem os saberes escolares, para então inserir estas problemáticas na constituição dos currículos.

Esta segunda tendência caracteriza as pesquisas de André Chervel e Marie- Madeleine Compère, historiadores do Institut National de Recherche Pédagogique (INRP) da França. A historiadora Marie-Madeleine Compère tem enfatizado a importância de se refazer a historiografia educacional para situar a escola em seus aspectos internos, denunciando as lacunas de uma produção que apenas buscou entendê-la pelo exterior, como instituição e como fruto de 
deliberações exclusivas das políticas públicas. Destaca a busca de novas fontes documentais que devem articular a leitura dos textos oficiais aos que são produzidos pela escola, tais como planos de aula dos professores, livros e manuais escolares, cadernos de alunos, provas e avaliações.

André Chervel, companheiro de Marie-Madeleine no artigo As humanidades no ensino, é um dos mais renomados pesquisadores franceses, tendo iniciado sua investigação sobre a história do ensino do Francês destacando a constituição das normas gramaticais como fruto de uma necessidade imposta pela escola. A partir desta pesquisa, Chervel aprofundou as análises e apresentou um significativo artigo, "A história das disciplinas escolares: reflexões sobre um campo de pesquisas", traduzido e publicado na revista Teoria \& Educação, em 1990. Chervel posicionou-se contra as proposições de Yves Chevallard, que enfatizava a dependência das disciplinas escolares em relação às ciências de referência, entendendo o saber escolar como transposição de um saber produzido pelo rigor metodológico científico para uma situação escolar, sendo que nessa passagem um conhecimento "superior" era transformado em um conhecimento "inferior", por intermédio de situações didáticas. Chervel rebelava-se contra esta concepção, por acreditar que ela derivava de um pressuposto que entendia a instituição escolar como simples agente de transmissão de saberes elaborados fora dela, e a origem desta idéia, segundo ele, compartilhada por muitos intelectuais e estudiosos e também pelo grande público, estava na convicção de que a escola é, por excelência, o lugar do conservadorismo, da inércia e da rotina. Para André Chervel, portanto, a concepção do saber escolar é fundamental para se entender e ultrapassar os pressupostos de uma visão que reforça a idéia de que os agentes históricos que promovem as mudanças estão exclusivamente fora da escola e que esta se transforma apenas pelas intervenções de elites intelectuais ou pelo poder político institucional. Aliando os pressupostos políticos aos epistemológicos, Chervel contribuiu para avanços na pesquisa ao demonstrar a ausência de neutralidade nos debates e nos métodos de estudos sobre disciplinas escolares. A história das disciplinas escolares, segundo Chervel, deve partir de uma concepção de disciplina entendida em suas especificidades, com objetivos próprios, que se articula com os demais saberes mas não forma um conhecimento menor, de segunda classe, e, nesta perspectiva, as pesquisas históricas devem se preocupar em entender suas especificidades e sua autonomia.

Chervel aprofundou estudos sobre cultura escolar, publicando um outro importante trabalho sobre os concursos públicos dos professores do ensino médio da França, indicando as relações entre os conteúdos de formação das Universidades e a constituição de uma cultura escolar (Histoire de l'agrégation. Contribution à l'histoire de la culture scolaire. INRP et Kimé, 1993). A inserção das disciplinas escolares na constituição de uma cultura escolar conduziu Chervel a situar e acompanhar historicamente os currículos. Nesta perspectiva, contribuiu com importante reflexão sobre os currículos do nível secundário com o artigo "Quando surgiu o ensino secundário?”, publicado pela Revista da Faculdade de Educação, em 1992. Nesse artigo, Chervel mostra as contradições, as conciliações e os ajustes do processo de construção do que se denomina de ensino secundário no decorrer dos séculos XIX e XX.

Completando suas pesquisas sobre esta problemática, ele apreende, de forma erudita e fundamentada, o percurso do currículo humanístico, suas transformações e articulações com o currículo científico e tecnológico, percurso este que se integra à nossa história da educação escolar, seguidores que fomos, ou temos sido, da produção educacional francesa.

Circe Maria Fernandes Bittencourt 